\title{
SISTEM PEMANTAUAN KUBIKEL TEGANGAN MENENGAH BERBASIS INTERNET OF THINGS
}

\author{
Nina Lestari ${ }^{1}$, Hadi Suwanto ${ }^{2}$, Rudy Gunawan ${ }^{3}$ \\ 1,2,3Program Studi Teknik Elektro, Fakultas Teknik, Universitas Sangga Buana \\ 1nina.lestari@usbypkp.ac.id
}

\begin{abstract}
ABSTRAK
Permasalahan yang sering terjadi di kubikel $20 \mathrm{kV}$ adalah korona, yaitu suatu fenomena yang terjadi pada saat udara di sekitar konduktor atau penghantar terionisasi akibat penurunan suhu naiknya kelembaban karena heater tidak aktif / rusak. Dari proses tersebut terjadilah pelepasan muatan yang mengakibatkan kegagalan isolasi pada udara, sehingga berpotensi merusak peralatan di dalam kubikel dan menghasilkan rugi-rugi daya. Oleh karena itu sistem pemantauan suhu dan kelembaban dapat menjadi satu solusi untuk meminimalisir efek korona pada kubikel. Sistem ini dirancang menggunakan sensor DHT22 untuk memantau suhu dan kelembaban serta NodeMCU sebagai mikrokontroler. Hasil dari pembacaan sensor ditampilkan pada web untuk diamati oleh petugas, sehingga dapat dilakukan deteksi dini kemunculan korona pada kubikel. Dari hasil pengujian, sensor dapat membaca suhu dan kelembaban sesuai dengan pengaturan heater yang terpasang pada kubikel $20 \mathrm{kV}$ dan hasil pengukuran sensor menunjukkan galat $0,3 \%$ serta dapat dimunculkan pada web yang dirancang untuk antarmuka dengan pengguna dan potensi.
\end{abstract}

Kata Kunci: Korona, Sensor DHT22, NodeMCU, Kelembaban, Suhu

\section{PENDAHULUAN}

Listrik merupakan sumber tenaga energi yang berperan penting dalam kehidupan sehari-hari. Hampir semua peralatan menggunakan energi listrik, hal ini menyebabkan meningkatnya kebutuhan energi listrik karena efisien dan membantu kemudahan dalam aktivitas sehari-hari[1].

Seiring dengan meningkatnya kebutuhan konsumen akan energi listrik, penyaluran energi listrik kepada konsumen diharapkan dapat berjalan secara optimal dan berkualitas. Salah satu elemen dari kualitas suplai listrik adalah ketahanan dan keamanan dari gangguan[2].

Gangguan yang terjadi sangatlah kompleks dan beraneka ragam, demikian pula dengan penyebab gangguan yang terjadi. Salah satu penyebab gangguan yang dapat menimbulkan masalah yang cukup serius pada jaringan listrik adalah korona pada kubikel. Korona sendiri adalah suatu fenomena yang terjadi pada saat udara di sekitar konduktor atau penghantar terionisasi. Dari proses tersebut terjadilah pelepasan muatan yang dapat mengakibatkan kegagalan isolasi pada udara[3].
Korona pada kubikel terjadi akibat tidak berfungsinya heater sebagai pemanas ruangan kubikel, sehingga suhu akan menurun dan kelembaban akan meningkat dan mengakibatkan timbulnya korona hingga kegagalan isolasi[4].

Jika kondisi ini tidak segera diatasi dapat mengakibatkan terjadinya hubung singkat antar penghantar dengan bumi dan dampaknya langsung berpengaruh pada terganggunya sistem distribusi tenaga listrik ke konsumen, juga terjadinya kerusakan atau kerugian material akan dialami oleh perusahaan[5].

Oleh karena itu diperlukan alat untuk memantau suhu dan kelembaban pada kubikel, sehingga meskipun heater tidak aktif dapat dilakukan penanganan secara cepat saat terjadi kejanggalan/kondisi tidak normal pada kubikel.

\section{TEORI PENDUKUNG}

Kubikel berfungsi sebagai penguhubung, pengendali, pelindung serta pembagi tenaga listrik. Kubikel sering diartikan juga sebagai peralatan switching dan kombinasinya, dilengkapi dengan peralatan pengukuran, kontrol dan proteksi, sedangkan kubikel 
tegangan menengah merupakan komponen listrik yang terhubung ke jaringan listrik tegangan menengah $20 \mathrm{kV}$.

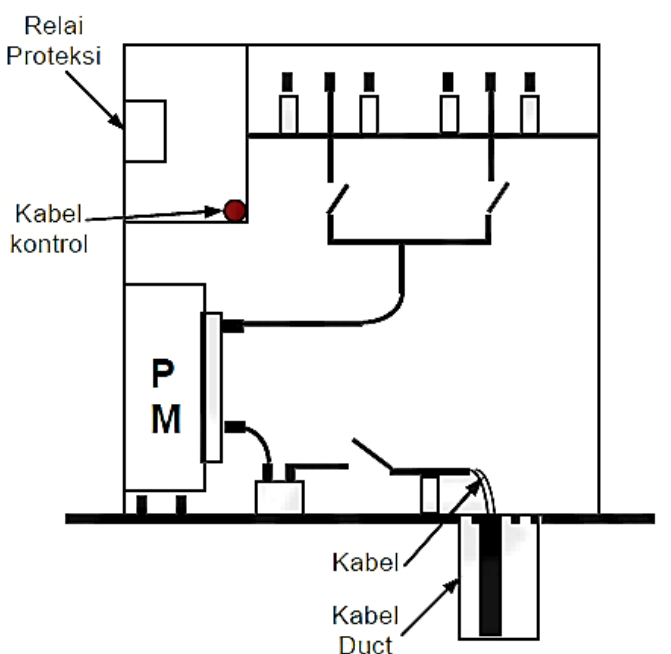

Gambar 1. Ilustrasi Kubikel Tegangan Menegah[6]

\subsection{Mikrokontroler}

NodeMCU adalah platform IoT yang bersifat open source. Terdiri dari perangkat keras dalam bentuk System on chip ESP8266. Istilah NodeMCU mengacu pada firmware digunakan oleh perangkat keras. NodeMCU dapat dianalogikan sebagai Arduino ESP8266. NodeMCU memiliki paket ESP8266 dan berbagai fitur mikrokontroler plus kemampuan akses ke wifi serta USB to serial, sehingga sangat cocok saat diimplementasikan dalam sistem monitoring[7].

\subsection{Sensor DHT22}

DHT22 adalah sensor yang berfungsi mengukur suhu dan kelembaban pada kubikel. Sensor pilih karena memiliki akurasi yang lebih baik daripada DHT11 dengan galat relatif pengukuran suhu $4 \%$ dan kelembaban $18 \%[8]$.

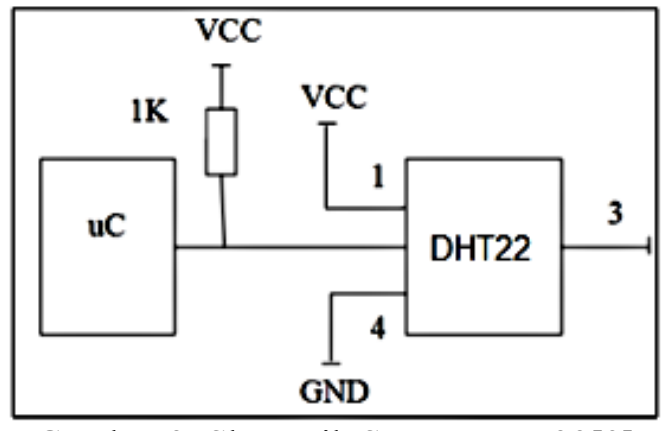

Gambar 2. Skematik Sensor DHT22[9]
Hasil pembacaan pada sensor kemudian diproses oleh modul NodeMCU, hasilnya akan ditampikan pada layar LCD dan web, sehingga user dapat mengetahui suhu pada kubikel secara real time

\subsection{PHP dan Database MYSQL}

PHP merupakan script yang terintegrasi dengan HTML dan berada pada server- server side HTML (embedded scripting). PHP adalah script yang digunakan untuk membuat halaman website yang dinamis. Dinamis berarti halaman yang akan ditampilkan dibuat saat halaman itu diminta oleh client. Mekanisme ini menyebabkan informasi yang diterima client selalu yang terbaru / up to date. Semua script PHP dieksekusi pada server dimana script tersebut dijalankan[10].

Aplikasi Database Management System (DBMS) MySQL digunakan untuk dapat mengelola basis data. Hal ini digunakan untuk menyimpan data pembacaan dari sensor untuk dapat ditampilkan pada web pengamatan. Alasan penggunaannya adalah karena MySQL menyimpan data secara logic dan struktur dua dimensi yang saling berhubungan dan merupakan salah satu basis data yang banyak digunakan secara umum.

\subsection{Liquid Crystal Display (LCD)}

Display yang digunakan adalah LCD 16x2. LCD 16x2 memetakan 16 garis karakter dan memiliki 2 garis tampilan per karakter untuk ditampilkan dalam matriks $5 \times 7$ piksel. Jenis LCD ini memiliki dua jenis register, command dan perintah data[8]. LCD digunakan sebagai display penampil perhitungan pembacaan sensor yang sudah diolah oleh Arduino Uno[11].

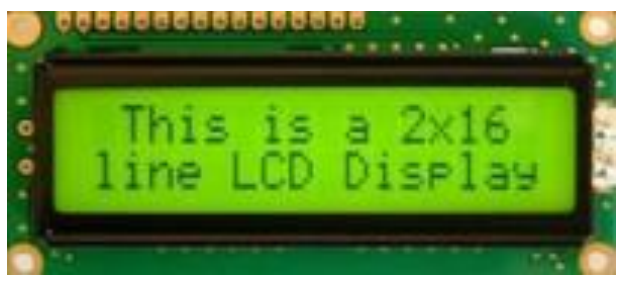

Gambar 3. LCD $16 \times 2$

\section{PERANCANGAN SISTEM}

Sistem yang dibuat merupakan embedded system berbasis internet of things (IoT), terdiri dari beberapa komponen seperti NodeMCU, sensor DHT22, LCD 16x2, RTC DS3231, PHP dan Web yang saling terintegrasi. Sistem 
ini dimanfaatkan untuk meningkatkan kehandalan jaringan $20 \mathrm{kV}$. Sistem berfungsi memantau suhu dan kelembaban pada kubikel sehingga pengguna dapat melihat data suhu dan kelembaban secara real time melalui web. Sistem ini merupakan pemberitahuan dini apabila heater pada kubikel tidak aktif. Heater pada kubikel diatur pada suhu $45^{\circ} \mathrm{C}$, Apabila suhu turun dibawah $30^{\circ} \mathrm{C}$ maka kelembaban akan naik dan menimbulkan kemungkinan terbentuknya korona.

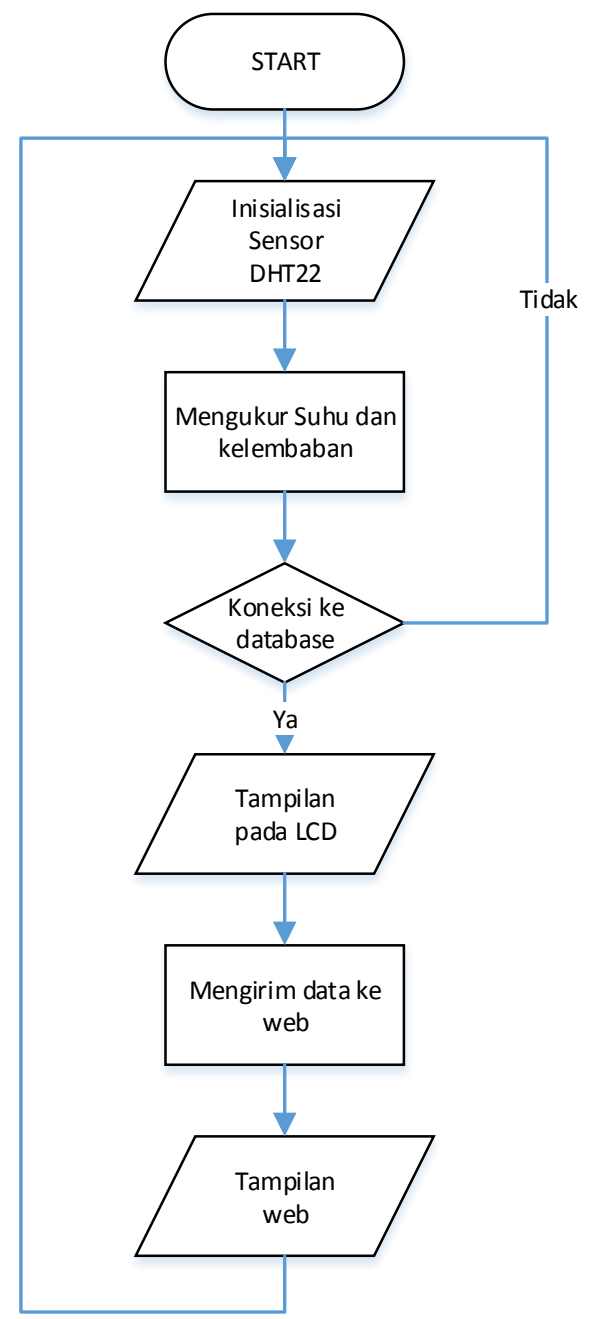

Gambar 5. Flowchart Sistem

Perangkat keras yang akan digunakan untuk membuat sistem monitoring kubikel $20 \mathrm{KV}$ ini menggunakan beberapa komponen, yaitu NodeMCU, sensor DHT22, LCD 16x2, RTC DS3231 dan kabel jumper. Kemudian rangkai semua komponen tersebut, lalu lakukan pemograman pada NodeMCU untuk setiap komponen yang terhubung menggunakan bahasa pemograman $\mathrm{C}$ agar dapat saling terintegrasi dan terhubung, agar dapat menampilkan pembacaan dari sensor ke web sehingga dapat memenuhi konsep IoT.

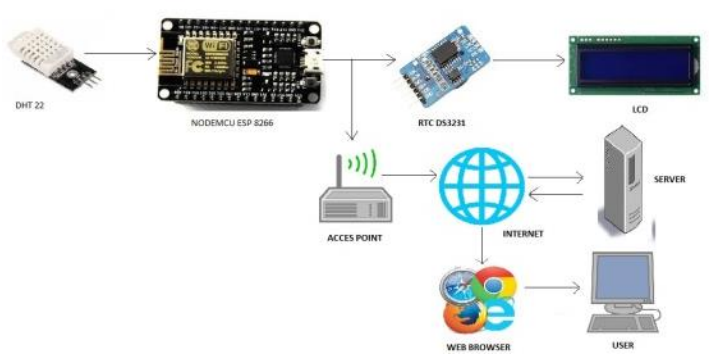

Gambar 4. Blok Diagram Sistem

Saat sensor DHT22 mendeteksi adanya perubahan suhu dan kelembaban pada kubikel, tampilan pembacaan suhu akan muncul pada LCD, kemudian apabila NodeMCU terhubung ke wifi, NodeMCU akan mengirimkan pembacaan sensor DHT22 ke web. Sensor DHT22 akan aktif terusmenerus untuk memantau kubikel selama NodeMCU terhubung ke power supply dan NodeMCU akan mengirimkan data ke web pada saat NodeMCU terhubung ke jaringan wifi.

\subsection{Perancangan Database}

Untuk memenuhi sistem yang akan dirancang, diperlukan struktur database yang terdiri dari tabel data suhu dan kelembaban. Struktur database yang digunakan ditunjukkan pada Tabel 1.

Tabel 1 Bentuk database hasil monitoring

\begin{tabular}{|c|c|c|c|}
\hline No & Waktu & Suhu & Kelembaban \\
\hline INT & TEXT & TEXT & TEXT \\
\hline INT & TEXT & TEXT & TEXT \\
\hline INT & TEXT & TEXT & TEXT \\
\hline
\end{tabular}

\subsection{Wiring Komponen}

Berikut merupakan gambar wiring. seluruh komponen dihubungkan dengan kabel jumper sesuai dengan pin yang sudah ditentukan.

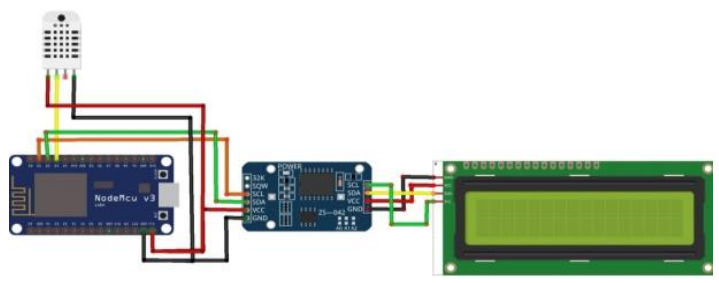

Gambar 6. Wiring Seluruh Komponen 


\section{PENGUJIAN SISTEM}

Pengujian sistem dilakukan di Gardu EEP dengan tipe gardu garpor PLN Rayon Bandung Utara.

\subsection{Pengujian Sensor DHT22}

Untuk memantau sensor suhu DHT22 dapat menggunakan serial monitor yang ada pada aplikasi arduino IDE.

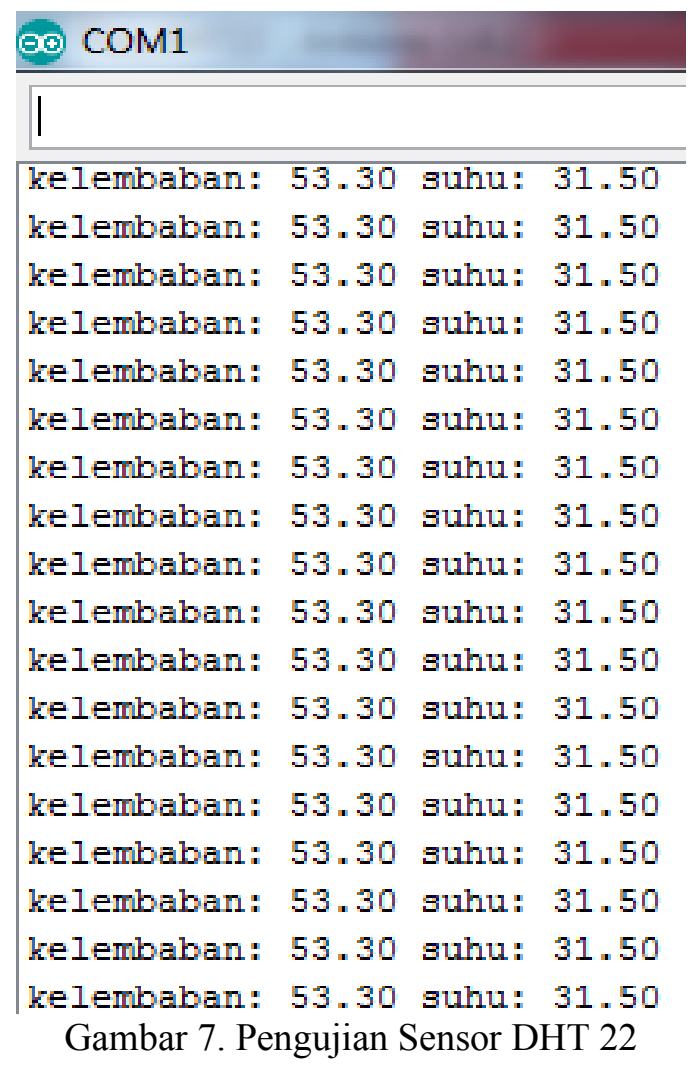

\subsection{Pengujian RTC DS3231 dan LCD}

Untuk Pengujian RTC DS 3231 dan LCD dapat dilihat langsung pada LCD yang ditunjukan pada gambar 8 berikut ini.

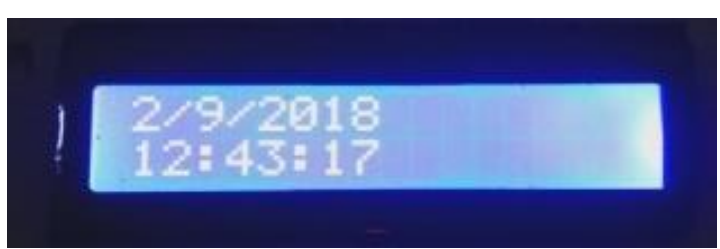

Gambar 8. Pengujian RTC DS323 dan LCD

\subsection{Pengujian Menghubungkan NodeMCU ke web hosting}

Hasil Pengujian koneksi NodeMCU ke web hosting dapat dilihat di serial monitor pada arduino IDE, ditunjukan pada gambar 9 berikut ini

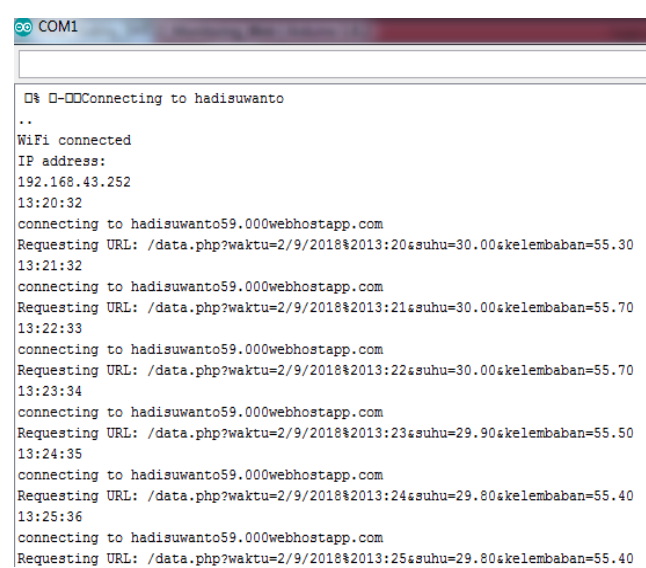

Gambar 9. Pengujian NodeMCU ke web hosting

\subsection{Hosting Database dan Script PHP}

Struktur data pada Tabel 1 direpresentasikan pada Gambar 10.

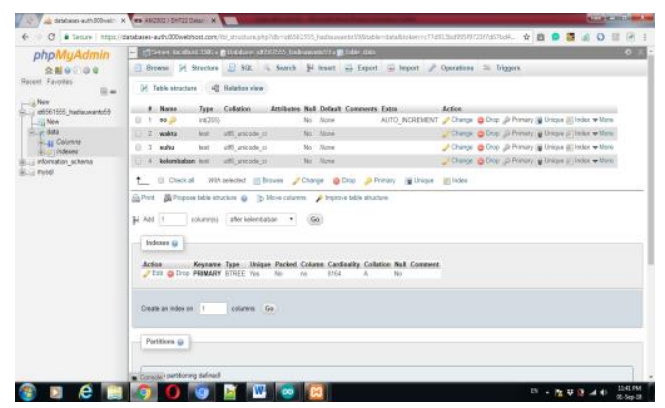

Gambar 10. Database yang telah di-hosting

Pada tahapan ini dibuat script untuk koneksi PHP, menampilkan data di web dan export data pembacaan sensor

\subsection{Pengujian Program Pengiriman Data Ke Web Hosting}

Gambar 11 menunjukkan pengujian web hosting dapat dilakukan dengan mengakses http://monitoringkubikel.000webhostapp.com pada web browser. Situs tersebut berfungsi untuk koneksi dari NodeMCU ke database yang di web hosting. Akses situs tersebut pada web browser yang menandakan NodeMCU dapat dikirimkan ke web hosting

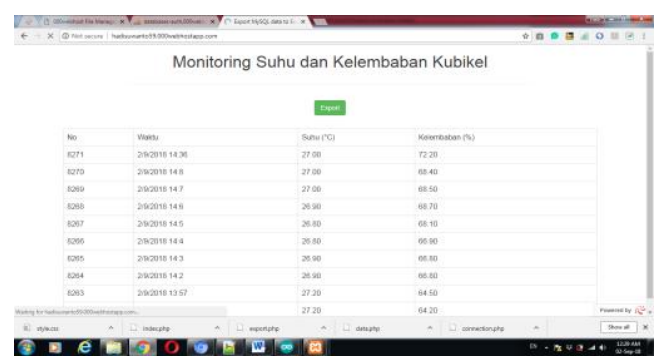

Gambar 11. Pengujian web hosting 


\subsection{Pengujian Pada Kubikel}

Pengujian ini dilakukan di dalam kubikel dengan memasukan sensor DHT22 ke dalam kubikel, Gambar 12 ini hasil data hasil pengujian kubikel yang telah di-export dari web.

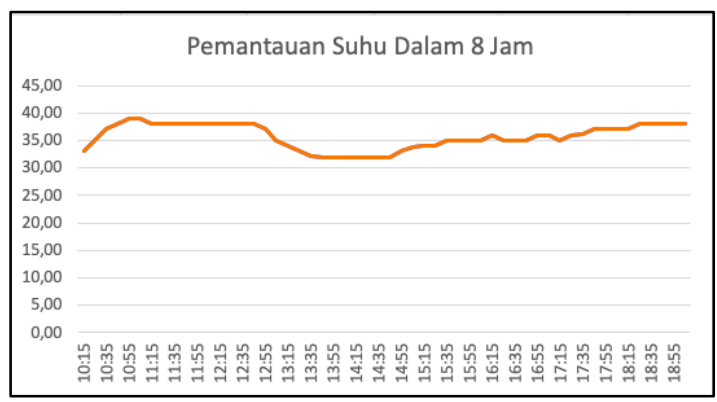

Gambar 12. Pemantauan suhu kubikel dalam 8 jam

Sementara Gambar 13 menunjukkan hasil pembacaan sensor kelembaban pada kubikel dengan simulasi pembacaan dilakukan selama 8 jam.

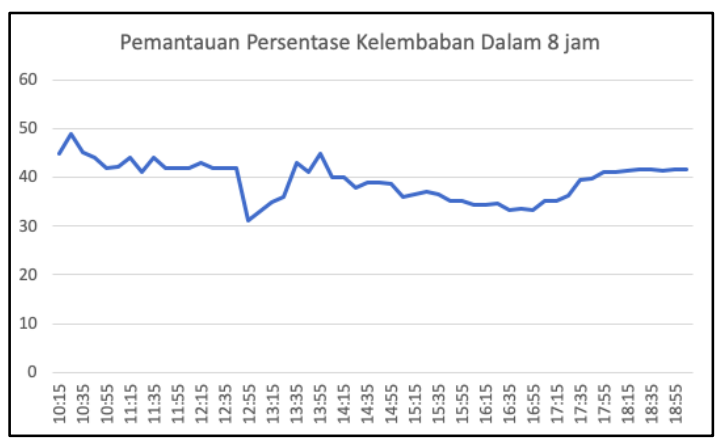

Gambar 13. Pemantauan persentase kelembaban kubikel dalam 8 jam

\section{KESIMPULAN}

Dapat ditarik beberapa kesimpulan berdasarkan hasil pengujian sistem, antara lain :

1. Sistem monitoring suhu dan kelembaban dapat direalisasikan dengan hasil pembacaan sensor suhu $32^{\circ} \mathrm{C}-39^{\circ} \mathrm{C}$ (di bawah $45^{\circ} \mathrm{C}$ ) dan kelembaban $31 \%$ - 49\% (di atas 30\%)

2. Hasil pembacaan sensor dapat dimunculkan di web dengan delay tampilan tergantung pada koneksi internet.

3. Sensor dapat membaca suhu dan kelembaban sesuai dengan pengaturan heater yang terpasang pada kubikel 20 $\mathrm{kV}$, dengan galat pembacaan sensor $0,3 \%$.

4. Sistem pemantauan membuat teknisi dapat lebih cepat melakukan penanganan untuk perbaikan dan lebih efektif dibanding dengan tanpa sistem pemantauan karena pemeliharaan kubikel biasanya dilakukan 6 bulan sekali.

Adapun beberapa pengembangan yang dapat dilakukan pada sistem, antara lian :

1. Sistem export data suhu dan kelembaban dapat dilakukan secara otomatis setiap bulan sebagai dasar menganalisis kondisi kubikel sehingga dapat dibuat sistem alarm.

2. Sistem yang dibuat bisa dikembangkan sebagai monitoring beban trafo di gardu distribusi dengan menambahkan sensor arus.

3. Database dilengkapi dengan lokasi kubikel agar teknisi dapat langsung menuju ke lokasi kubikel yang memerlukan perbaikan.

\section{DAFTAR PUSTAKA}

[1] A. Solih and J. Jamaaluddin, "Rancang Bangun Pengaman Panel Distribusi Tenaga Listrik Di Lippo Plaza Sidoarjo Dari Kebakaran Berbasis Arduino Nano," JEEEU (Journal Electr. Electron. Eng., 2017, doi: 10.21070/jeee-u.v1i2.1171.

[2] A. Akmal and K. Abimanyu, "Studi Pengaturan Relay Arus Lebih dan Relay Hubung Tanah Penyulang Timor 4 Pada Gardu Induk Studi Kasus Gardu Induk Dawuan," J. Infotronik, 2017.

[3] N. Pasra, A. Makkulau, and M. O. Abriyanto, "Analisa Efek Korona Pada Sistem Distribusi Tenaga Listrik 20 kV Pada Gardu Beton," $J$. Ilm. SUTET, vol. 8, no. 2, pp. 103-113, 2018, [Online]. Available: https://stt-pln.ejournal.id/sutet/article/view/235.

[4] H. Yin, T. Cui, and X. Meng, "Research on the method to restrain the corona happened in switch cubicle," in 2010 China International Conference on Electricity Distribution, CICED 2010, 2010.

[5] Z. Munggaran, "RANCANG BANGUN KONTROL SUHU DAN KELEMBABAN PADA SISTEM DISTRIBUSI TENAGA LISTRIK KUBIKEL 20 kV," Cimahi, 2015. doi: 10.13140/RG.2.1.1817.0000.

[6] D. Bosco, "Analisis dan Simulasi Tegangan Awal Terbentuknya Korona Pada Model Kubikel,” Depok, 2008. [Online]. Available: http://lib.ui.ac.id/file?file=digital/123969- 
R030807.pdf.

[7] A. G. Azwar, R. Haviani Laluma, R. P. Halim, Nurwathi, Gunawansyah, and Gunawan, "Smart Trash Monitoring System Design Using NodeMCU-based IoT," in TSSA 2019 - 13th International Conference on Telecommunication Systems, Services, and Applications, Proceedings, 2019, doi: 10.1109/TSSA48701.2019.8985517.

[8] A. H. Saptadi, "Perbandingan Akurasi Pengukuran Suhu dan Kelembaban Antara Sensor DHT11 dan DHT22 Studi Komparatif pada Platform ATMEL AVR dan Arduino," J. Inform. dan Elektron., 2015, doi: 10.20895/infotel.v6i2.73.

[9] M. Bogdan, "How to Use the DHT22 Sensor for Measuring Temperature and Humidity with the Arduino Board," ACTA Univ. Cibiniensis, 2017, doi: 10.1515/aucts-20160005.

[10] J. S. Informasi, H. Hanafiah, A. Pirmansyah, D. S. Informasi, and M. S. Informasi, "Pembangunan sistem informasi kepegawaian berbasis web di kantor desa manggungharja," J. Sist. Inf. Karya Anak Bangsa, vol. 01, no. 01, pp. 47-52, 2019, [Online].

Available: http://ejournal.unibba.ac.id/index.php/jsika/article/download/246/216/.

[11] Elektronika Dasar, "LCD (Liquid Cristal Display)," Elektronika-Dasar.Web.Id. 2012. 